\title{
Comparison of Several Regression Procedures for Method Comparison Studies and Determination of Sample Sizes
}

\author{
Application of linear regression procedures for method comparison studies \\ in Clinical Chemistry, Part II
}

\section{By H. Passing}

Abt. für Praktische Mathematik, Hoechst AG, Frankfurt am Main 80, and

\section{W. Bablok}

Allg. Biometrie, Boehringer Mannheim GmbH, Mannheim

(Received October 18, 1983/February 27, 1984)

Summary: In part I of this series (H. Passing \& W. Bablok (1983), J. Clin. Chem. Clin. Biochem. 21, 709-720) we described a new biometrical procedure for the evaluation of method comparison studies. In part II we now discuss its properties and compare them with those of other established procedures by means of a simulation study. We demonstrate that the reliability of the results not only depends on the sample size but also on the sampling distribution, the precision of the methods, and the concentration range covered by the samples. Linear regression and principal component procedures are either inadequate or not as reliable as our new procedure. The appropriate sample size is discussed and recommendations are given.

Vergleich verschiedener Regressionsverfahren für Methodenvergleichsstudien und Bestimmung von Stichprobenumfängen

Anwendung von linearen Regressionsverfahren bei Methodenvergleichsstudien in der Klinischen Chemie, Teil II

Zusammenfāssuing: Im ersten Teil unserer Arbeit ( $H$. Passing \& W. Bablok (1983), J. Clin. Chem. Clin. Biochem. 21, 709-720) haben wir ein neues biometrisches Verfahren zur Auswertung von Methodenvergleichen vorgestellt. Im zweiten Teil nun werden seine Eigenschaften untersucht und im Rahmen einer Simulationsstudie mit denen anderer, bereits etablierter Verfahren verglichen. Wir zeigen, daß die Zuverlässigkeit der Auswertungsergebnisse nicht nur vom Stichprobenumfang, sondern auch von der Stichprobenverteilung, der Präzision der Methoden und dem Konzentrationsbereich der Proben abhängt. Lineare Regression und die Hauptkomponenten-Verfahren sind entweder unzulänglich oder nicht so zuverlässig wie das neue Verfahren. Die Abhängigkeit des Stichprobenumfanges von den Randbedingungen wird diskutiert, und Empfehlungen werden gegeben. 


\section{Contents}

1. Introduction

2. Evaluation Procedures for Method Comparison

3. The Simulation Model

4. Comparison of Procedures $P_{1}$ to $P_{7}$ if $\beta=1$

4.1 The probability of a false positive test result if no extreme values are present

4.2 The bias of the slope estimates if no extreme values are present

4.3 The influence of extreme measurement values

4.4 Very small size of measurement range

4.5 The influence of a non-constant CV on the behaviour of the procedures

4.6 The influence of the sample size on the above results

\subsection{Recommendations}

5. The Sample Size

5.1 The probability of a positive test result

5.2 Determination of the sample size

6. Conclusion

\section{Introduction}

In part I of our paper (1) we described a new statistical linear regression procedure which can be employed in the evaluation of method comparison studies. We showed its theoretical advantages compared with other statistical procedures and presented an example with real data to support our arguments.

In this paper we present the comparison of our procedure with other established procedures in order to demonstrate its merits. Further we shall expose the strong dependence of the appropriate sample size on certain properties which are inherent in the analytical methods for which a comparison should be performed.

The experimental design consists of drawing $n$ independent samples from a population and measuring the analyte in question with each of the two methods. The evaluation usually consists of fitting a straight line $Y=\alpha+\beta X$ to the data and in testing the hypotheses $\beta=1$ and $\alpha=0$. The evaluation procedures discussed here differ with regard to the estimators, the meaning of $\beta$ and $\alpha$, and the tests of the hypotheses. The statistical models on which an evaluation can be based are discussed in part I. The notation and meaning of $\mathrm{X}$ and $\mathrm{Y}$ will be the same as in part $\mathrm{I}$.

In this context we should like to point out that the problem of determining the parameters of a linear equation by which one method is transformed into the other is a different one. It deserves a separate treatment and will be the topic of part III of our paper.

\section{Evaluation Procedures for Method Comparison}

The evaluation procedures discussed in this paper are divided in two groups, one which is invariant with regard to the assignment of the methods to $X$ and $Y$, and one which is not. A procedure is invariant, if after interchanging $X$ and $Y$ the respective estimators of $\beta$ and $\alpha$ can be transformed into each other, and if the test of the hypotheses $\beta=1$ and $\alpha=0$ gives the same results under both assignments.

\subsection{Invariant procedures}

The invariant procedures asume that the variation of the observed values $x_{i}$ and $y_{i}$ has two independent sources: one is the variation within the population of all possible samples, the other one is the measurement error within each sample. This leads to the partition

$$
x_{i}=x_{i}^{*}+\xi_{i} \text { and } y_{i}=y_{i}^{*}+\eta_{i}
$$

where $x_{i}^{*}$ and $y_{i}^{*}$ are the expected values within the $\mathrm{i}$-th sample and $\zeta_{\mathrm{i}}$ and $\eta_{\mathrm{i}}$ are the measurement errors. The procedures assume the structural relationship

$$
y_{i}^{*}=\alpha+\beta x_{i}^{*}
$$

between the expected values.

Procedure $P_{I}$ : This is our new procedure as described in part $I$. The estimators of $\beta$ and $\alpha$ are both medians. The usual statistics, such as mean, standard deviation and correlation coefficient are not required. The hypothesis tests do not ask for any specific distributional assumptions. ,

Procedure $P_{2}$ : Standardized principal component analysis (2). Its estimators are based on means and standard deviations; the tests require certain distributional properties of the data.

Procedure $P_{3}$ : Principal component analysis $(2,3)$. The theoretical background is identical to that of $P_{2}$ and the test of the hypothesis $\beta=1$ is the same; the estimators, however, involve in addition the coefficient of correlation.

\subsection{Procedures which are not invariant}

These procedures assume that one variable is free of random variation implying that it is fixed.

The underlying statistical models are given by

$$
\begin{array}{ll}
y_{i}=\alpha+\beta x_{i}+\eta_{i} & \text { with fixed } x_{i} \text { or } \\
x_{i}=A+B y_{i}+\xi_{i} & \text { with fixed } y_{i} .
\end{array}
$$

\subsubsection{Procedures assuming $X$ to be fixed}

Procedure $P_{4}$ : Theil's procedure (4): This is similar to $P_{1}$, in particular the estimator of $\beta$ is also a medi- 
an. The test of the hypothesis $\beta=1$ is distributionfree. Theil does not give an estimator for $\alpha ; \alpha$ may be estimated as in $\mathbf{P}_{1}$.

Procedure $P_{s}$ : This is the classical linear regression based on least squares (5). Its estimators are based on means, standard deviations and the correlation coefficient (as for $\mathrm{P}_{2}$ and $\mathrm{P}_{3}$ ); the tests require certain distributional properties of the underlying data.

\subsubsection{Procedures asuming $Y$ to be fixed}

Procedure $P_{6}$ is identical to procedure $P_{4}$ and procedure $P_{7}$ identical to procedure $P_{5}$, only the assignment of the methods to $X$ and $Y$ is interchanged. (If the arithmetical evaluation of a method comparison is carried out by a procedure which is not invariant then usually both $\mathrm{P}_{4}$ and $\mathrm{P}_{6}$, or $\mathrm{P}_{5}$ and $\mathrm{P}_{7}$ are calculated.)

\section{The Simulation Model}

If the same data set is evaluated by the procedures $P_{1}$ to $P_{7}$ the estimators of $\beta$ and $\alpha$ usually yield different results. Moreover, the results of testing the hypotheses $\beta=1$ and $\alpha=0$ are not necessarily identical. Therefore it is desirable to know which procedure really gives the correct result.

Each of the 7 procedures is based on certain mathematical assumptions which are different or even contrary to each other. If the properties of the real data meet the assumptions of a particular procedure it will give a reliable result; otherwise the result may be biased. Therefore, a given data set may satisfy the assumptions of one procedure but not of the other one so that systematic differences between the results can be expected. If we restrict ourselves to the slope $\beta-$ and $\beta$ is the most important parameter in such an evaluation - then deviations may occur in two respects:

Firstly, an estimator b of $\beta$ may be biạsed in so far that it achieves values which are systematically larger (or smaller) than $\beta$. Hence b would not estimate $\beta$ but anything else resulting possibly in an erroneous judgement of the methods. Consequently an unbiased estimation of $b$ in realistic situations is a desirable property.

Secondly, testing the hypothesis $\beta=1$ for the estimated slope $b$ may result in a significant difference even though $\beta=1$ is true. If the mathematical assumptions of the test are met the probability of such a false positive result is restricted to the level $\gamma$ (e.g. $\gamma=5 \%$ ). Otherwise the actual level - that is the true probability of obtaining a false positive result under the given circumstances - may be much higher than the nominal level of $\gamma$ on which the test is performed. Consequently, an evaluation procedure becomes inappropriate if significant differences between the two methods would be found too frequently. Therefore, a second desirable property of a procedure is to achieve the level $\gamma$ of probability in realistic situations.

It follows that a procedure gives the correct result if its actual level is about $\gamma$ and if its estimator of the slope is unbiased.

Obviously both properties cannot be studied by evaluating real data sets, since the true relation between both methods is not known. They can, however, be judged by the results of simulation experiments (6). Here data sets describing a well defined "situation" are repeatedly generated to study the behaviour of $P_{1}$ to $P_{7}$ in detail. Our simulation is based on the structural relationship model which gives a reasonable description of reality. Since procedures $\mathrm{P}_{4}$ to $\mathrm{P}_{7}$ are frequently used in method comparison studies we have included these procedures in the simulation study. From the structural relationship model, it follows that the CV's of the methods can be defined from the variances $\sigma_{\xi}^{2}$ and $\sigma_{\eta}^{2}$ of their respective measurement errors. For ease of notation, however, we shall use $C V_{x}$ and $C V_{y}$ when we refer to the coefficient of variation of method $X$ or method $Y$ respectively.

Before we describe the details of the simulation model we state the following general assumptions:

- There is a linear relationship between method $\mathrm{X}$ and method $Y$.

- The measurements of $X$ and $Y$ are realisations of independent continuous bivariate variables.

Let $\left[c_{u}, c_{0}\right]$ be the range of measurements for the method assigned to $X$, and $\left[\beta c_{u}, \beta c_{0}\right]$ the corresponding range for the method assigned to $Y$. Let $c=\frac{c_{0}}{c_{u}}$ be the common size of both ranges with $1<c<\infty$. A large size corresponding to $c \geqslant 8$ will be represented by $\mathrm{c}=\infty$, a medium size corresponding to $4 \leqslant c<8$ by $\mathrm{c}=4$. Further, a small size of $2 \leqslant \mathrm{c}<4$ will be modelled by $\mathrm{c}=2$ and a very small size of $1.25 \leqslant \mathrm{c}<2$ by $c=1.25$. Since every method has a lower detection limit there is always $c_{u}>0$.

As a measure of precision which is known before the start of a method comparison experiment, we use the coefficient of variation. In the simulation model we assume $\mathrm{CV}_{\mathrm{x}}$ and $\mathrm{CV}_{\mathrm{y}}$ to be constant over their concentration range ${ }^{1}$ ). This is much more realistic than

1) The CV is chosen here as a familiar measure of precision. In 1.c. (7) it is shown that other measures may be more appropriate if the distribution of the measurement error is skew or has a kurtosis, but this property is without relevance in this context. 
the usual assumption of constant standard deviations $(2,5)$. For completeness sake, we also studied the influence of non-constant CV's on the evaluation procedures. The magnitude of the CV's is not independent of the size $c$ of the measurement range since methods for constituents with a very small biological range (as for instance electrolytes) require small CV's for the differentiation of measurements. Therefore, the CV's are varied independently of each other from $2 \%$ to $13 \%$ for a medium or large size $\mathrm{c}$ and from $2 \%$ to $10 \%$ for a small size $\mathrm{c}$. In the case of a very small size the CV's are varied from $1 \%$ to $2 \%$.

It can be shown that it is sufficient to take the interval $\left[\frac{1}{c}, 1\right]$ for $X$ and the interval $\left[\frac{\beta}{c}, \beta\right]$ for $Y$ as common range, whereby both CV's remain unchanged. This does not cause any loss of generality, but achieves independence from the real size of the measurement values.

In the simulation model, $\mathrm{n}$ samples are drawn from the interval $\left[\frac{1}{c}, 1\right]$; the $i$-th sample has expected values $x_{i}^{*}$ and $y_{i}^{*}=\beta x_{i}^{*}$. (Since we study the estimation of $\beta$ we assume a constant $\alpha$ and set it equal to zero).

The samples are generated from

- a uniform sampling distribution over $\left[\frac{1}{c}, 1\right]$, represented by equidistant $x_{i}^{*}$, or

- a skew sampling distribution over $\left[\frac{1}{c}, 1\right]$ : to achieve this the interval is divided into 5 sections of equal length with equidistant $x_{i}^{*}$ covering $5 \%$, $50 \%, 30 \%, 10 \%$ and $5 \%$ of $n$. In this way the measurements are concentrated more in the left part of the range. This distribution corresponds to many real situations where usually samples come both from healthy and diseased persons.

The choice of predefined $x_{i}^{*}$ from the uniform and skew sampling distribution actually leads to a functional relationship model. However, our first investigations demonstrated that the results from the simulation on the basis of a true structural relationship model (with random generation of $x_{i}^{*}$ ) did not differ from those of the functional relationship model. Considering the amount of computing time needed for the simulation we decided to use the less demanding functional relationship model. Besides, this model can be interpreted as a special case of the structural relationship model.

In order to estimate $\beta$ reliably it would be optimal to have the samples located at the boundaries of the range as long as linearity is guaranteed. Obviously, this sampling distribution will be insufficient for practical reasons. However, the uniform distribution lies between this extreme and the usually skew sampling distribution and is attainable.

The expected values are distorted by independent measurement errors $\xi_{\mathrm{i}}$ and $\eta_{\mathrm{i}}$ giving "measurement values" $x_{i}=x_{i}^{*}+\xi_{i}$ and $y_{i}=y_{i}^{*}+\eta_{i}$. These errors correspond to the precision of the methods. Three types of distribution of measurement errors are considered:

- $\xi_{\mathrm{i}}$ and $\eta_{\mathrm{i}}$ are normally distributed.

- $\xi_{i}$ and $\eta_{i}$ both have a mixture of two normal distributions differing slightly from each other so that the resulting distributions of $\xi_{i}$ and $\eta_{i}$ look like a normal distribution; in particular they are symmetric.

- $\xi_{\mathrm{i}}$ and $\eta_{\mathrm{i}}$ both have a skew distribution with a positive kurtosis so that they differ essentially from a normal distribution.

The latter two distributions are chosen since it is well known $(8,9)$ that in general the measurement errors are not normally distributed. Therefore it is advisable to investigate several distributions.

So far the simulation does not allow for large differences between $x_{i}$ and $y_{i}$ that occur frequently in real experiments. We call such a pair $\left(x_{i}, y_{i}\right)$ an extreme value. It may be caused by a difference in specificity or by susceptibility to interferences of the methods and should not be removed from the evaluation without any experimental reason. Hence it is necessary to consider extreme values in the simulation model; they are introduced to the data by changing some values of $\mathrm{Y}$ up to $\pm 50 \%$.

In summing up we define one simulation step by the following parameters: $c=$ common size of ranges, $n$ = sample size, $\mathrm{CV}_{\mathrm{x}}, \mathrm{CV}_{\mathrm{y}}, \beta$, sampling distribution, distribution of measurement errors and number and position of extreme values.

In our basic simulation model $n$ pairs $\left(x_{i}, y_{i}\right)$ are generated for each choice of simulation parameters. The estimators $b_{1}, \ldots, b_{7}$ of the slope are calculated according to $P_{1}, \ldots, P_{7}$, and the hypothesis $\beta=1$ is tested with respect to $P_{1}, \ldots, P_{7}$. These steps are performed 500 times for each choice of the simulation parameters. From the $500 b_{i}$ 's the median med $\left(b_{i}\right)$ is calculated. The bias of $b_{i}$ is estimated (med $\left.\left(b_{i}\right)-\beta\right)$. The proportion of significant test results given by $P_{i}$ is an estimator of the actual level of $=P_{i}$ if $\beta=1$. The 7 procedures are compared with regard to their actual level and to their bias, if $\beta=1$. The case $\beta \neq 1$ deserves a separate investigation. As the maximum 
sample size we choose $\mathrm{n}=90$ since otherwise the simulation expenditure would be too large. The influence of extreme values is not investigated and only normally distributed measurement errors are considered. The probability of a significant test result if $\beta \neq 1$ is true, is called the power. It is tabulated for several parameter combinations. The power should be large if there is a relevant difference between $\beta$ and 1 . Therefore the user must define a relevant value, $\beta_{\text {rcl }}$, which is adequate to his specific problem. Then, if $\beta$ is larger than $\beta_{\text {rel }}$ or less than $1 / \beta_{\text {rel }}$ the power should be sufficiently large, say $\geqslant 80 \%$. It is shown that this desirable property depends on the suitable choice of the sample size $n$. A list of such sample sizes is given.
Since it is difficult to assess the properties of an experimental data set with respect to the model assumptions of a regression procedure, we find it more advantageous to demonstrate how a procedure behaves if certain assumptions are not met.

\section{Comparison of Procedures $P_{1}$ to $P_{7}$ if $\beta=1$}

4.1 The probabillity of a false positive test result if no extreme values are present

We demonstrate the results of the simulation study for the sample size $n=40$. The probabilities obtained for a false positive test result are accurate up to $\pm 2 \%$. A summary is given in table 1 , where $C V_{x}$ $\leqslant \mathrm{CV}_{\mathrm{y}}$ is assumed without loss of generality. The

Tab. 1. Actual probability of a false positive test result for $n=40(\gamma=5 \%)$; no extreme values are present.

$P_{1}=$ our new procedure
$P_{2}=$ standardized principal component analysis
$P_{3}=$ principal component analysis
$P_{4}=$ Theil's procedure, $X$ assumed to be fixed
$P_{5}=$ least squares linear regression, $X$ assumed to be fixed
$P_{6}=$ Theil's procedure, $X$ assumed to be fixed
$P_{7}=$ least squares linear regression, $Y$ assumed to be fixed

\begin{tabular}{|c|c|c|c|c|c|c|c|c|c|c|c|c|c|c|c|c|c|c|c|c|c|c|c|c|c|c|}
\hline \multirow[b]{3}{*}{ c } & \multirow[b]{3}{*}{$\begin{array}{l}C V_{x} \\
(\%)\end{array}$} & \multirow[b]{3}{*}{$\begin{array}{l}C V_{y} \\
(\%)\end{array}$} & \multicolumn{6}{|c|}{$\begin{array}{l}\text { Samples: uniform } \\
\text { Errors: normal }\end{array}$} & \multicolumn{6}{|c|}{$\begin{array}{l}\text { Samples: skew } \\
\text { Errors: normal }\end{array}$} & \multicolumn{6}{|c|}{$\begin{array}{l}\text { Samples: uniform } \\
\text { Errors: mixture of normals }\end{array}$} & \multicolumn{6}{|c|}{$\begin{array}{l}\text { Samples: uniform } \\
\text { Errors: skew with kurtosis }\end{array}$} \\
\hline & & & \multicolumn{2}{|c|}{ Invariạnt } & \multicolumn{4}{|c|}{ Not invariant } & \multicolumn{2}{|c|}{ Invariant } & \multicolumn{4}{|c|}{ Not invariant } & \multicolumn{2}{|c|}{ Invariant } & \multicolumn{4}{|c|}{ Not invariant } & \multicolumn{2}{|c|}{ Invariant } & \multicolumn{4}{|c|}{ Not invariant } \\
\hline & & & $P_{1}$ & $\begin{array}{l}\mathbf{P}_{2} \\
\mathbf{P}_{3}\end{array}$ & $P_{4}$ & $P_{5}$ & $P_{6}$ & $P_{7}$ & $P_{1}$ & $\begin{array}{l}P_{2} \\
P_{3}\end{array}$ & $\mathrm{P}_{4}$ & $P_{5}$ & $P_{6}$ & $P_{7}$ & $\mathbf{P}_{1}$ & $\begin{array}{l}P_{2} \\
P_{3}\end{array}$ & $P_{4}$ & $P_{5}$ & $P_{6}$ & $P_{7}$ & $P_{1}$ & $\begin{array}{l}P_{2} \\
P_{3}\end{array}$ & $P_{4}$ & $P_{5}$ & $P_{6}$ & $P_{7}$ \\
\hline & 2 & 2 & 5 & 6 & 4 & 7 & 5 & 7 & 5 & 17 & 5 & 17 & 6 & 18 & 4 & 5 & 4 & 5 & 4 & 5 & 5 & 6 & 5 & 7 & 6 & 7 \\
\hline & 2 & 5 & 6 & 8 & 6 & 8 & 6 & 11 & 6 & 17 & 6 & 18 & 9 & 2 & 6 & 6 & 7 & 7 & 7 & 8 & 6 & 16 & 6 & 10 & 7 & 23 \\
\hline & 2 & 7 & 7 & 10 & 6 & 8 & 10 & 16 & 6 & 19 & 6 & 15 & 10 & 29 & 5 & 8 & 6 & 7 & 6 & 13 & 7 & 17 & 6 & 9 & 8 & 30 \\
\hline & 5 & 7 & 6 & 8 & 7 & 9 & 9 & 14 & 6 & 20 & 10 & 23 & 9 & 23 & 7 & 10 & 9 & 11 & 9 & 12 & 6 & 10 & 7 & 8 & 9 & 18 \\
\hline & 5 & 10 & 5 & 8 & 5 & 8 & 10 & 19 & 9 & 21 & 7 & 18 & 20 & 31 & 6 & 7 & 6 & 9 & 9 & 15 & 8 & 16 & 8 & 9 & 12 & 16 \\
\hline & 7 & 7 & 5 & 7 & 7 & 12 & 6 & 11 & 5 & 21 & 7 & 23 & 12 & 27 & 4 & 6 & 5 & 10 & 5 & 9 & 6 & 9 & 9 & 13 & 10 & 13 \\
\hline & 7 & 10 & 6 & 10 & 7 & 8 & 10 & 19 & 6 & 19 & 8 & 24 & 16 & 27 & 5 & 8 & 7 & 11 & 7 & 14 & 7 & 13 & 8 & 12 & 13 & 25 \\
\hline & 7 & 13 & 7 & 9 & 7 & 11 & 15 & 29 & 11 & 24 & 10 & 22 & 30 & 45 & 7 & 11 & 6 & 9 & 14 & 27 & 8 & 15 & 7 & 7 & 16 & 41 \\
\hline & 10 & 13 & 7 & 8 & 9 & 16 & 15 & 26 & 9 & 19 & 12 & 26 & 25 & 39 & 6 & 7 & 6 & 12 & 12 & 20 & 7 & 11 & 9 & 11 & 13 & 33 \\
\hline & 13 & 13 & 6 & 8 & 10 & 20 & 13 & 24 & 8 & 17. & 19 & 32 & 19 & 33 & 5 & 7 & 11 & 21 & 11 & 18 & 6 & 11 & 12 & 24 & 12 & 22 \\
\hline 4 & 2 & 2 & 4 & 5 & 5 & 6 & 4 & 7 & 5 & 14 & 6 & 14 & 6 & 15 & 6 & 5 & 5 & 7 & 6 & 6 & 4 & 5 & 5 & 5 & 5 & 7 \\
\hline & 2 & 5 & 5 & 8 & 4 & 7 & 8 & 15 & 8 & 16 & 7 & 14 & 17 & 28 & 5 & 7 & 6 & 5 & 7 & 11 & 7 & 16 & 5 & 9 & 11 & 27 \\
\hline & 2 & 7 & 4 & 7 & 4 & 4 & 12 & 22 & 9 & 16 & 5 & 12 & 29 & 36 & 6 & 8 & 6 & 7 & 10 & 19 & 8 & 17 & 4 & 5 & 16 & 39 \\
\hline & 5 & 7 & 4 & $i$ & 8 & 11 & 11 & 18 & 8 & 17 & 10 & 18 & 23 & 31 & 5 & 5 & 6 & 7 & 10 & 15 & 7 & 9 & 10 & 12 & 9 & 20 \\
\hline & 5 & 10 & 8 & 11 & 5 & 9 & 25 & 41. & 12 & 17 & 7 & 17 & 47 & 17 & 7 & 11 & 5 & 7 & 19 & 29 & 10 & 17 & 6 & 7 & 23 & 49 \\
\hline & 7 & 7 & 5 & 6 & 10 & 15 & 10 & 15 & 6 & 12 & 20 & 26 & 20 & 26 & 3 & 5 & 7 & 12 & 11 & 13 & 9 & 9 & 12 & 18 & 13 & 20 \\
\hline & 7 & 10 & 6 & 9 & 8 & 11 & 27 & 37 & 8 & 16 & 15 & 21 & 40 & 46 & 7 & 7 & 9 & 13 & 18 & 23 & 9 & 13 & 10 & 12 & 25 & 40 \\
\hline & 7 & 13 & 9 & 12 & 7 & 10 & 39 & 55 & 14 & 18 & 10 & 20 & 68 & 68 & 8 & 12 & 6 & 9 & 29 & 44 & 9 & 18 & 9 & 9 & 35 & 58 \\
\hline & 10 & 13 & 6 & 6 & 13 & 20 & 29 & 42 & 8 & 14 & 26 & 31 & 61 & 62 & 5 & 6 & 12 & 17 & 22 & 36 & 7 & 11 & 14 & 19 & 30 & 47 \\
\hline & 13 & 13 & 6 & 7 & 24 & 34 & 28 & 43 & 7 & 10 & 49 & 53 & 49 & 52 & 5 & 7 & 20 & 30 & 21 & 32 & 4 & 7 & 24 & 37 & 27 & 37 \\
\hline 0 & 2 & 2 & 5 & 6 & 5 & 8 & 7 & 8 & 6 & 8 & 8 & 12 & 10 & 12 & 6 & 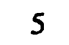 & 6 & 8 & 4 & 7 & 5 & 5 & 6 & 8 & 5 & 7 \\
\hline & 2 & 5 & 7 & 9 & 6 & 6 & 19 & 30 & 16 & 17 & 6 & 11 & 51 & 54 & 7 & 11 & 7 & 8 & 19 & 2 & 6 & 12 & 5 & 6 & 21 & 41 \\
\hline & 2 & 7 & 13 & 17 & 4 & 6 & 45 & 58 & 24 & 26 & 5 & 9 & 77 & 77 & 9 & 12 & 3 & 4 & 35 & 4 & 14 & 26 & 4 & 4 & 43 & 68 \\
\hline & 5 & 7 & 7 & 9 & 9 & 13 & 34 & 44 & 11 & 16 & 24 & 25 & 64 & 63 & 6 & 7 & 10 & 12 & 27 & 3 & 6 & 8 & 10 & 14 & 34 & +7 \\
\hline & 5 & 10 & 16 & 21 & 7 & 10 & 66 & 79 & 25 & 29 & 14 & 21 & 93 & 29 & 12 & 16 & 8 & 10 & 51 & 66 & 12 & 23 & 10 & 9 & 63 & 79 \\
\hline & 7 & 7 & 5 & 5 & 24 & 33 & 25 & 35 & 5 & 7 & 47 & 51 & 49 & 5 & 5 & 6 & 19 & 25 & 21 & 28 & 7 & 7 & 25 & 35 & 25 & 33 \\
\hline & 7 & 10 & 8 & 10 & 16 & 21 & 56 & 71 & 15 & 19 & 30 & 34 & 88 & 87 & 7 & 10 & 13 & 19 & 44 & 56 & 7 & 9 & 8 & 24 & 52 & 68 \\
\hline & 10 & 10 & 4 & 4 & 39 & 52 & 45 & 56 & 5 & 8 & 76 & 77 & 73 & 75 & 4 & 5 & 36 & 46 & 33 & 45 & 7 & 8 & 40 & 52 & 43 & 55 \\
\hline
\end{tabular}


properties of the individual procedures are discussed in the light of the overall results from the simulation; they are available on request. We give the interpretation on the basis of differences in CV's:

1. Both CV's are identical: $P_{1}$ achieves its nominal level rather well for all simulation parameters (see also part I). In many cases, however, $\mathrm{P}_{2}$ and $\mathrm{P}_{3}$ show insufficient results particularly if the size is large and the sampling distribution is skew; then they exceed their nominal level considerably. The procedures $\mathrm{P}_{4}, \mathrm{P}_{5}, \mathrm{P}_{6}$ and $\mathrm{P}_{7}$ are far away from their nominal level unless both CV's are small. To illustrate an actual level of about $50 \%$ one could say that the outcome of a method comparison can be obtained by tossing a coin.

II. Both CV's are approximately identical, say $1<\frac{C V_{y}}{C V_{x}}<1.5$. Here $P_{1}$ is the best of all procedures in meeting the nominal level for all simulation parameters, but it does occasionally exceed $\gamma=5 \%$. If the size $c$ is large and the sampling distribution is skew then $\mathrm{P}_{2}$ and $\mathrm{P}_{3}$ exceed their nominal level considerably. If the size $c$ is small the actual levels of $P_{1}, P_{2}, P_{3}$ are essentially higher than in case $I$. The actual levels of $P_{6}$ and $P_{7}$ are higher, and those of $P_{4}$ and $P_{5}$ are lower when compared with case $I$.

III. Both CV's are rather different, say $1.5<\frac{C_{y}}{C_{x}}$ $<2.5$ : Then $\mathrm{P}_{4}$ is the procedure with the best result but it can also exceed $\gamma$. However, if both CV's are less than $7 \%$ and the sampling distribution is uniform then $P_{1}$ also meets the level $\gamma$ rather well in contrast to $\mathrm{P}_{2}$ and $\ddot{P}_{3} . \mathrm{P}_{5}$ has a higher level than $\mathrm{P}_{4}$. In comparison with case II the levels of $P_{4}$ and $P_{5}$ are decreased whereas those of $P_{6}$ and $P_{7}$ are further increased.

IV. Both CV's are essentially different, say $\frac{C_{y}}{C V_{x}}$ $>$ 2.5: Then $\mathrm{P}_{4}$ achieves $\gamma=5 \%$, whereas the level of $P_{5}$ is in most of the cases higher. $P_{1}, P_{2}$, and $P_{3}$ may also exceed $\gamma=5 \%$ considerably. The levels of $\mathrm{P}_{6}$ and $\mathrm{P}_{7}$ can go as far as $100 \%$.

These results are plausible: If both CV's are very different then $\mathrm{X}$ might be considered to be free of random variation relative to $Y$, so that $P_{4}$ and $P_{5}$ will be appropriate; in contrast $P_{6}$ and $P_{7}$ are completely inappropriate. $P_{4}$ is superior to $P_{5}$ since $P_{4}$ is distribution-free. If, however, both CV's are identical then no variable can be assumed to be free of random variation, and $\mathrm{P}_{1}, \mathrm{P}_{2}$ or $\mathrm{P}_{3}$ will be applicable. $\mathrm{P}_{1}$ is superior to $P_{2}$ and $P_{3}$ since it is not based on any distributional assumptions.
It can be seen that the actual level of $P_{1}$ is more independent of the sampling distribution than that of $P_{2}$ or $\mathrm{P}_{3}$, especially in the case of a large $\mathrm{c}$ which is typical for most of the applications. It is obvious from the results that it does not make sense to perform both $\mathrm{P}_{4}$ and $\mathrm{P}_{6}$ or $\mathrm{P}_{5}$ and $\mathrm{P}_{7}$ since it is likely that the test results will contradict each other.

\subsection{The bias of the slope estimators if no extreme values are present}

Again the sample size is restricted to $n=40$. The resulting bias is accurate up to $\pm 1 \%$. Table 2 shows the bias of $b_{1}, \ldots, b_{7}$ in per.cent of $\beta=1$ in correspondence to table 1 .

Procedures $P_{1}, P_{2}$ and $P_{3}$ show the same degree of bias if no extreme values are present. If any bias occurs then $b_{1}, b_{2}$ and $b_{3}$ overestimate $\beta$ whereas $b_{4}$ and $b_{5}$ underestimate $\beta . b_{6}$ and $b_{7}$ underestimate $\beta$ as well; however, in table 2 the bias of $\frac{1}{b_{6}}$ and $\frac{1}{b_{7}}$ is given in order to demonistrate that $b_{4}$ and $b_{6}$ or $b_{5}$ and $b_{7}$ are quite different and that they do not correspond to each other. $b_{4}$ and $b_{5}$ have a similar bias, if any, and the same holds true for $b_{6}$ and $b_{7}$. The bias increases if $c$ becomes smaller or the CV's are increased. As before we discuss four cases:

I. $\mathrm{CV}_{\mathrm{x}}=\mathrm{CV}_{\mathrm{y}}$ : The slope estimators of the invariant procedures $P_{1}, P_{2}$ and $P_{3}$ can be judged to be unbiased. The other procedures, however, may produce rather heavily biased results.

II. $1<\frac{C V_{y}}{C V_{x}}<1.5: b_{1}, b_{2}$ and $b_{3}$ often are nearly unbiased. But they show a bias if the size $c$ is small or if the sampling distribution is skew.

III. $1.5<\frac{\mathrm{CV}_{\mathrm{y}}}{\mathrm{CV}_{\mathrm{x}}}<2.5:$ Here $\mathrm{b}_{4}$ and $\mathrm{b}_{5}$ are the least biased estimators. If both CV's are less than 7\% and if the sampling distribution is uniform then the invariant procedures also have only a small bias.

IV. $\frac{C_{\mathrm{y}}}{\mathrm{CV}_{\mathrm{x}}}>2.5: \mathrm{b}_{4}$ and $\mathrm{b}_{5}$ do not show an appreciable bias whereas $b_{1}, b_{2}$ and $b_{3}$ may be strongly biased; $b_{6}$ and $b_{7}$ are highly biased.

If an estimator is biased the corresponding actual test level is increased. The inverse, however, is not true. The test level may be highly increased even though the estimator is unbiased - caused by a violation of the corresponding distributional assumptions. Therefore $P_{1}$ with no distributional assumptions is superior to $P_{2}$ and $P_{3}$, and $P_{4}$ is superior to $P_{5}$ even if extreme values do not occur. 


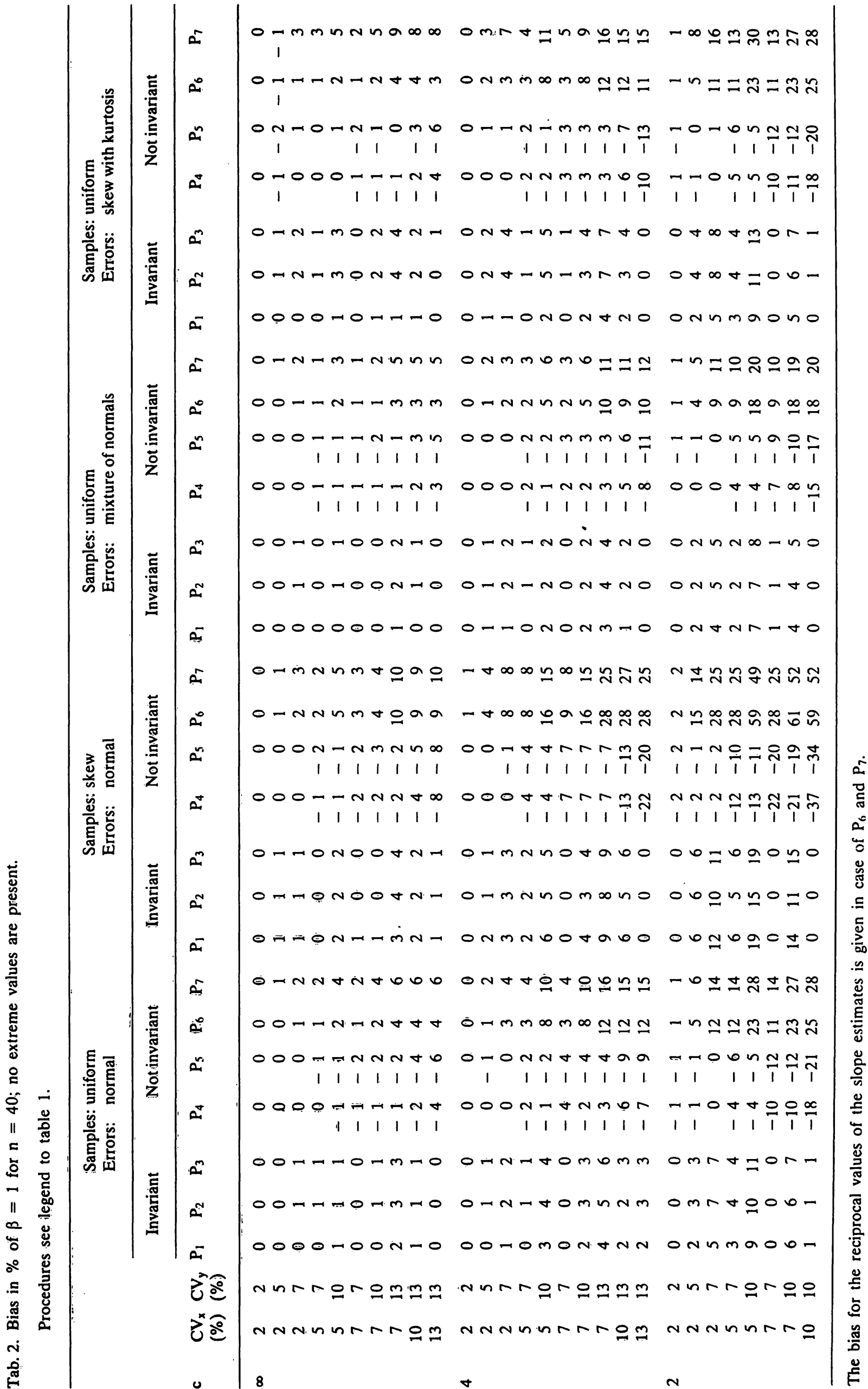


4.3 The influence of extreme measurement values

We now consider the case that some of the measurement values of $Y$ differ distinctly from the corresponding values of $X$; the sample size is $n=40$. $5 \%$ of the measurement values are systematically biased in the following manner: If the expected values $y_{i}^{*}$ are sorted to $y_{(1)}^{*} \leqslant \cdots \leqslant y_{(40)}^{*}$, then $y_{(30)}^{*}$ is decreased either by $50 \%$ or by $50 \%$ of the amount $1-\frac{1}{c}$ whichever is the smaller. In the same way $y_{(40)}^{*}$ is increased by $50 \%$ or by $50 \%$ of the amount $1-\frac{1}{c}$. Clearly, $\mathrm{y}_{(40)}^{*}$ lies outside the common range of both methods; but since the actual range of $Y$ must be larger when extreme values are present, it is a realistic model. Table 3 shows the probability of a false positive test result, i.e. the actual test level, and table 4 gives the bias of $b_{1}, \ldots, b_{7}$ in per cent of $\beta=1$.
The actual level achieved by $P_{1}$ is equal to or slightly higher than $\gamma=5 \%$, if both CV's are approximately identical - provided the sampling distribution is uniform. If the sampling distribution is skew and the size $c$ not large then the actual level of $P_{1}$ may be considerably higher than $5 \%$. Procedure $\mathrm{P}_{4}$ meets its nominal level very well provided that both CV's are rather different. $b_{1}$ tends to be biased particularly if the sampling distribution is skew and $\mathrm{c}$ is not large.

The actual level of $P_{2}$ and $P_{3}$ exceeds $\gamma=5 \%$ by far, and is substantially higher than that of $P_{1}$ for all simulation parameters. If the sampling distribution is skew and the precision of both methods is high it can go up to $100 \%$ : here $P_{2}$ and $P_{3}$ would declare both methods to be significantly different even though $\beta=1$ is true. Both $b_{2}$ and $b_{3}$ are biased particularly if the sampling distribution is skew.

Now we consider the influence of the number of extreme values and their location (below or above the

Tab. 3. Probability of a false positive test result for $n=40(\gamma=5 \%)$; two extreme values are present.

Procedures see legend to table 1 .

\begin{tabular}{|c|c|c|c|c|c|c|c|c|c|c|c|c|c|c|}
\hline \multirow[b]{3}{*}{ c } & \multirow[b]{3}{*}{$\begin{array}{l}C V_{x} \\
(\%)\end{array}$} & \multirow[b]{3}{*}{$\begin{array}{l}C V_{y} \\
(\%)\end{array}$} & \multicolumn{6}{|c|}{$\begin{array}{l}\text { Samples: uniform } \\
\text { Errors: normal }\end{array}$} & \multicolumn{6}{|c|}{$\begin{array}{l}\text { Samples: skew } \\
\text { Errors: normal }\end{array}$} \\
\hline & & & \multicolumn{2}{|c|}{ Invariant } & \multicolumn{4}{|c|}{ Not invariant } & \multicolumn{2}{|c|}{ Invariant } & \multicolumn{4}{|c|}{ Not invariant } \\
\hline & & & $P_{1}$ & $\begin{array}{l}P_{2} \\
P_{3}\end{array}$ & $P_{4}$ & $P_{5}$ & $P_{6}$ & $P_{7}$ & $P_{1}$ & $\begin{array}{l}\mathbf{P}_{2} \\
\mathbf{P}_{3}\end{array}$ & $P_{4}$ & $P_{5}$ & $P_{6}$ & $\mathrm{P}_{7}$ \\
\hline \multirow[t]{10}{*}{$\infty$} & 2 & 2 & 4 & 22 & 3 & 0 & 8 & 100 & 7 & 100 & 6 & 91 & 11 & 100 \\
\hline & 2 & 5 & 7 & 38 & 6 & 0 & 14 & 99 & 6 & 100 & 5 & 74 & 19 & 100 \\
\hline & 2 & 7 & 9 & 42 & 5 & 0 & 19 & 99 & 8 & 100 & 4 & 63 & 27 & 100 \\
\hline & 5 & 7 & 6 & 35 & 5 & 0 & 15 & 94 & 6 & 99 & 3 & 46 & 22 & 100 \\
\hline & 5 & 10 & 9 & 41 & 4 & 1 & 24 & 93 & 14 & 96 & 5 & 45 & 40 & 100 \\
\hline & 7 & 7 & 7 & 26 & 3 & 1 & 14 & 90 & 5 & 97 & 4 & 36 & 21 & 100 \\
\hline & 7 & 10 & 7 & 32 & 3 & 1 & 19 & 89 & 8 & 91 & 6 & 31 & 33 & 99 \\
\hline & 7 & 13 & 8 & 34 & 5 & $i$ & 25 & 87 & 11 & 87 & 4 & 28 & 49 & 99 \\
\hline & 10 & 13 & 7 & 28 & 5 & $i$ & 25 & 83 & 8 & 81 & 8 & 16 & 44 & 98 \\
\hline & 13 & 13 & 9 & 24 & 8 & 2 & 25 & 82 & 6 & 69 & 8 & 9 & 40 & 96 \\
\hline \multirow[t]{10}{*}{4} & 2 & 2 & 7 & 15 & 3 & 0 & 13 & 100 & 8 & 100 & 3 & 13 & 20 & 100 \\
\hline & 2 & 5 & 8 & 28 & 4 & 0 & 20 & 98 & 14 & 100 & 4 & 22 & 44 & 100 \\
\hline & 2 & 7 & 8 & 36 & 4 & 0 & 27 & 97 & 23 & 98 & 5 & 23 & 65 & 100 \\
\hline & 5 & 7 & 7 & 24 & 3 & 0 & 27 & 90 & 12 & 90 & 4 & 10 & 56 & 100 \\
\hline & 5 & 10 & 14 & 34 & 5 & 1 & 42 & 94 & 26 & 88 & 3 & 16 & 82 & 100 \\
\hline & 7 & 7 & 6 & 20 & 5 & 0 & 23 & 86 & 8 & 79 & 9 & 6 & 50 & 99 \\
\hline & 7 & 10 & 8 & 27 & 4 & 0 & 40 & 89 & 18 & 77 & 6 & 6 & 71 & 100 \\
\hline & 7 & 13 & 12 & 33 & 5 & 1 & 56 & 94 & 25 & 81 & 6 & 7 & 90 & 100 \\
\hline & 10 & 13 & 8 & 22 & 9 & 4 & 49 & 87 & 16 & 64 & 15 & 4 & 83 & 97 \\
\hline & 13 & 13 & 5 & 15 & 12 & 11 & 45 & 83 & 9 & 44 & 33 & 11 & 77 & 95 \\
\hline \multirow[t]{8}{*}{2} & 2 & 2 & 5 & 17 & 2 & 0 & 15 & 99 & 8 & 100 & 4 & 7 & 29 & 100 \\
\hline & 2 & 5 & 10 & 37 & 2 & 0 & 40 & 96 & 31 & 97 & 3 & 11 & 81 & 100 \\
\hline & 2 & 7 & 20 & 47 & 4 & 2 & 66 & 96 & 48 & 94 & 3 & 11 & 95 & 100 \\
\hline & 5 & 7 & 11 & 26 & 5 & 2 & 54 & 91 & 23 & 75 & 10 & 3 & 90 & 100 \\
\hline & 5 & 10 & 18 & 39 & 5 & 4 & 79 & 98 & 49 & 83 & 8 & 4 & 99 & 100 \\
\hline & 7 & 7 & 4 & 12 & 16 & 10 & 43 & . 81 & 7 & 43 & 36 & 9 & 80 & 97 \\
\hline & 7 & 10 & 11 & 25 & 10 & 7 & 73 & 94 & 26 & 62 & 23 & 7. & 97 & 100 \\
\hline & 10 & 10 & 5 & 10 & 30 & 32 & 61 & 85 & 6 & 27 & 60 & 37 & 91 & 97 \\
\hline
\end{tabular}


Tab. 4. Bias in $\%$ of $\beta$ for $n=40$; two extreme values are present.

Procedures sec legend to table 1.

\begin{tabular}{|c|c|c|c|c|c|c|c|c|c|c|c|c|c|c|c|c|}
\hline \multirow[b]{3}{*}{ c } & \multirow[b]{3}{*}{$\begin{array}{l}C V_{k} \\
(\%)\end{array}$} & \multirow[b]{3}{*}{$\begin{array}{l}C V_{y} \\
(\%)\end{array}$} & \multicolumn{7}{|c|}{$\begin{array}{l}\text { Samples: uniform } \\
\text { Errors: normal }\end{array}$} & \multicolumn{7}{|c|}{$\begin{array}{l}\text { Samples: skew } \\
\text { Errors: normal }\end{array}$} \\
\hline & & & \multicolumn{3}{|c|}{ Invariant } & \multicolumn{4}{|c|}{ Not invariant } & \multicolumn{3}{|c|}{ Invariant } & \multicolumn{4}{|c|}{ Not invariant } \\
\hline & & & $\mathbf{P}_{\mathbf{1}}$ & $\mathbf{P}_{\mathbf{2}}$ & $\mathbf{P}_{3}$ & $P_{4}$ & Ps & $P_{h}$ & $P_{7}$ & $P_{1}$ & $\mathbf{P}_{2}$ & $\mathbf{P}_{3}$ & $P_{4}$ & $P_{s}$ & $P_{h}$ & $P_{7}$ \\
\hline \multirow[t]{10}{*}{$x$} & 2 & 2 & () & 10 & 11 & () & 4 & 0 & 16 & 1 & 24 & 25 & 0 & 16 & 1 & 32 \\
\hline & 2 & 5 & 1 & 11 & 11 & 0 & 5 & 1 & 16 & 2 & 25 & 26 & 1 & 16 & 3 & 33 \\
\hline & 2 & 7 & 1 & 11 & 12 & 1 & 5 & 2 & 18 & 2 & 25 & 27 & 1 & 16 & 5 & 33 \\
\hline & 5 & 7 & 2 & 11 & 11 & 0 & 4 & 3 & 18 & 2 & 23 & 26 & 0 & 15 & 5 & 33 \\
\hline & 5 & 10 & 2 & 12 & 12 & 1 & 4 & 5 & 19 & 4 & 25 & 28 & () & 16 & 10 & 37 \\
\hline & 7 & 7 & 1 & 10 & 10 & 0 & 3 & 3 & 18 & 2 & 23 & 25 & -1 & 14 & 7 & 33 \\
\hline & 7 & 10 & 2 & 11 & 11 & () & 3 & 5 & 19 & 3 & 24 & 27 & -2 & 13 & 10 & 35 \\
\hline & 7 & 13 & 3 & 12 & 13 & -1 & 2 & 7 & 22 & 6 & 26 & 28 & -1 & 12 & 13 & 39 \\
\hline & 10 & 13 & 3 & 11 & 12 & $-i$ & 1 & 8 & 22 & 5 & 25 & 28 & -3 & 11 & 15 & 41 \\
\hline & 13 & 13 & 3 & 10 & 11 & -3 & -1 & 8 & 23 & 4 & 23 & 27 & -7 & 7 & 16 & 41 \\
\hline \multirow[t]{10}{*}{4} & 2 & 2 & 1 & 11 & 12 & 0 & 4 & 1 & 19 & 1 & 26 & 29 & 0 & 15 & 3 & 39 \\
\hline & 2 & 5 & 2 & 11 & 12 & 0 & 3 & 3 & 20 & 4 & 27 & 30 & 1 & 15 & 9 & 41 \\
\hline & 2 & 7 & 3 & 13 & 14 & 1 & 3 & 7 & 22 & 8 & 28 & 32 & 1 & 15 & 15 & 45 \\
\hline & 5 & 7 & 3 & 11 & 13 & -1 & 1 & 7 & 22 & 7 & 27 & 31 & -2 & 11 & 16 & 45 \\
\hline & 5 & 10 & 5 & 12 & 14 & () & 1 & 11 & 25 & 13 & 30 & 36 & -1 & 12 & 28 & 52 \\
\hline & 7 & 7 & 2 & 10 & 11 & -2 & -1 & 8 & 22 & 5 & $\cdot 24$ & 28 & -6 & 7 & 18 & 43 \\
\hline & 7 & 10 & 5 & 12 & 13 & -2 & -1 & 12 & 25 & 10 & 27 & 32 & -6 & 8 & 28 & 49 \\
\hline & 7 & 13 & 7 & 14 & 17 & -2 & -1 & 18 & 33 & 16 & 31 & 39 & -6 & 7 & 41 & 59 \\
\hline & 10 & 13 & 6 & 12 & 14 & -6 & -6 & 19 & 33 & 13 & 27 & 35 & -13 & 1 & 45 & 59 \\
\hline & 13 & 13 & 4 & 10 & 12 & -9 & -9 & 19 & 33 & 8 & 21 & 28 & -21 & -8 & 47 & 59 \\
\hline \multirow[t]{8}{*}{2} & 2 & 2 & 1 & 10 & 11 & 0 & 2 & 3 & 19 & 3 & 27 & 31 & -2 & 13 & 7 & 43 \\
\hline & 2 & 5 & 4 & 13 & 14 & 0 & 3 & 10 & 23 & 13 & 31 & 36 & 0 & 12 & 25 & 52 \\
\hline & 2 & 7 & 9 & 16 & 18 & 1 & 2 & 16 & 32 & 22 & 35 & 43 & 0 & 12 & 41 & 61 \\
\hline & 5 & 7 & 7 & 13 & 16 & -4 & -3 & 18 & 32 & 16 & 29 & 37 & -11 & 2 & 45 & 61 \\
\hline & 5 & 10 & 12 & 17 & 22 & -5 & -4 & 30 & 43 & 32 & 37 & 52 & -9 & 2 & 79 & 85 \\
\hline & 7 & 7 & 4 & 10 & 11 & -9 & -9 & 18 & 32 & 10 & 22 & 29 & -21 & -8 & 49 & 61 \\
\hline & 7 & 10 & 9 & 15 & 19 & -9 & -9 & 32 & 45 & 24 & 30 & 44 & -20 & -7 & 79 & 82 \\
\hline & 10 & 10 & 5 & 9 & 12 & -18 & -18 & 32 & 45 & 10 & 19 & 31 & -36 & -23 & 82 & 82 \\
\hline
\end{tabular}

regression line). Table 5 shows the simulated cases, where the extreme values are obtained as described above. Table 6 states the respective probability of a false positive test result and the bias of procedures $P_{1}, P_{2}$ and $P_{3}$ if both CV's are $7 \%$ (in this constellation procedures $P_{4}, P_{5}, P_{6}, P_{7}$ are completely inadequate).

Täb. 5. Distribution of the extreme values for $n=40$.

\begin{tabular}{llll}
\hline $\begin{array}{l}\text { Number of } \\
\text { extreme } \\
\text { values }\end{array}$ & $\begin{array}{l}\% \\
\text { of } \\
\mathrm{n}\end{array}$ & $\begin{array}{l}\text { Position in the } \\
\text { sort sequence } \\
\text { of the } \mathrm{y}_{\mathrm{i}}^{\mathrm{i}}\end{array}$ & $\begin{array}{l}\text { Location with } \\
\text { respect to } \\
\text { regression line }\end{array}$ \\
\hline 1 & 2.5 & 40 & above \\
2 & 5.0 & 30 & $\begin{array}{l}\text { below } \\
\text { above }\end{array}$ \\
3 & 7.5 & 40 & $\begin{array}{l}\text { below } \\
\text { above } \\
\text { above }\end{array}$ \\
\hline
\end{tabular}

Tab. 6. Actual probability of a false positive test result $(y=5 \%)$ and bias in $\%$ of $\beta=1$ for $n=40$ and $C V_{x}=C V_{y}=7 \%$, depending on the number and distribution of extreme values.

Procedures see legend to table 1.

\begin{tabular}{|c|c|c|c|c|c|c|c|c|c|c|c|c|}
\hline \multirow[b]{3}{*}{$\mathbf{C}$} & \multicolumn{2}{|c|}{$\begin{array}{l}\text { Extreme } \\
\text { values }\end{array}$} & \multicolumn{5}{|c|}{$\begin{array}{l}\text { Samples: uniform } \\
\text { Errors: normal }\end{array}$} & \multicolumn{5}{|c|}{$\begin{array}{l}\text { Samples: skew } \\
\text { Errors: normal }\end{array}$} \\
\hline & \multirow{2}{*}{$\begin{array}{l}\text { Num- } \\
\text { ber }\end{array}$} & \multirow{2}{*}{$\begin{array}{l}\% \\
\text { of } \\
n\end{array}$} & \multicolumn{3}{|c|}{$\begin{array}{l}\text { Actual } \\
\text { level }\end{array}$} & \multicolumn{2}{|l|}{ Bias } & \multicolumn{3}{|c|}{$\begin{array}{l}\text { Actual } \\
\text { level }\end{array}$} & \multicolumn{2}{|l|}{ Bias } \\
\hline & & & $P_{1}$ & $\begin{array}{l}P_{2} \\
P_{3}\end{array}$ & $P_{1}$ & $P_{2}$ & $P_{3}$ & $P_{1}$ & $\begin{array}{l}P_{2} \\
P_{3}\end{array}$ & $P_{1}$ & $P_{2}$ & $P_{3}$ \\
\hline \multirow[t]{4}{*}{$x$} & 0 & 0 & 5 & 7 & 0 & 0 & 0 & 5 & 21 & 1 & 0 & 0 \\
\hline & 1 & 2.5 & 9 & 57 & 2 & 11 & 11 & 5 & 97 & 2 & 22 & 24 \\
\hline & 2 & 5 & 7 & 26 & 1 & 10 & 10 & 5 & 97 & 2 & 23 & 25 \\
\hline & 3 & 7.5 & 11 & 77 & 3 & 16 & 18 & 12 & 99 & 4 & 29 & 33 \\
\hline \multirow[t]{4}{*}{4} & 0 & 0 & 5 & 6 & 0 & 0 & 0 & 6 & 12 & 0 & 0 & 0 \\
\hline & 1 & 2.5 & 8 & 33 & 2 & 10 & 10 & 7 & 81 & 3 & 22 & 25 \\
\hline & 2 & 5 & 6 & 20 & 2 & 10 & 11 & 8 & 79 & 5 & 24 & 28 \\
\hline & 3 & 7.5 & 10 & 62 & 5 & 18 & 21 & 15 & 97 & 8 & 35 & 41 \\
\hline \multirow[t]{4}{*}{2} & 0 & 0 & 5 & 5 & 0 & 0 & 0 & 5 & 7 & 0 & 0 & 0 \\
\hline & 1 & 2.5 & 6 & 16 & 3 & 9 & 10 & 7 & 40 & 4 & 18 & 24 \\
\hline & 2 & 5 & 4 & 12 & 4 & 10 & 11 & 7 & 43 & 10 & 22 & 29 \\
\hline & 3 & 7.5 & 10 & 34 & 8 & 16 & 20 & 17 & 74 & 16 & 32 & 45 \\
\hline
\end{tabular}


The probability of a false positive test result obtained by $P_{1}$ can be higher than $\gamma=5 \%$ and $b_{1}$ may be biased. $P_{2}$ and $P_{3}$, however, exceed the nominal level to a much greater extent and show a considerably greater bias. The extreme point located at the upper boundary of the range of $\mathrm{X}$ and above the regression line causes most of these effects whereas the extreme value located inside the range and below the regression line does not show any extra effect. An additional extreme value near the upper boundary of the range of $X$ and above the line increases the effect.

Therefore, if there is at least one extreme value present $P_{1}$ is superior to $P_{2}$ and $P_{3}$ since the results given by $P_{1}$ are only slightly impaired. This property holds for both a uniform and a skew sampling distribution; it is a generalization of our example in part I of this paper.

\subsection{Very small size of measurement range}

All previous statements hold also for a very small size $c$, but all effects are amplified even when the precision of both methods is high. Table 7 shows the probability of a false positive test result and the bias of $b_{1}, b_{2}$ and $b_{3}$ if two extreme values are present (see 4.3). The interpretation is obvious.

Tab. 7. Actual probability of a false positive test result $(\gamma=5 \%)$ and bias in $\%$ of $\beta=1$ for $c=1.25$ and $n=40$; two extreme values are present.

Procedures see legend to table 1 .

\begin{tabular}{|c|c|c|c|c|c|c|c|c|c|c|c|}
\hline \multirow[b]{3}{*}{$\begin{array}{l}C V_{x} \\
(\%)\end{array}$} & \multirow[b]{3}{*}{$\begin{array}{l}C V_{y} \\
(\%)\end{array}$} & \multicolumn{5}{|c|}{$\begin{array}{l}\text { Samples: uniform } \\
\text { Errors: normal }\end{array}$} & \multicolumn{5}{|c|}{$\begin{array}{l}\text { Samples: skew } \\
\text { Errors: normal }\end{array}$} \\
\hline & & \multicolumn{3}{|c|}{$\begin{array}{l}\text { Actual } \\
\text { level }\end{array}$} & \multicolumn{2}{|c|}{ Bias } & \multicolumn{2}{|c|}{$\begin{array}{l}\text { Actual } \\
\text { level }\end{array}$} & \multicolumn{3}{|c|}{ Bias } \\
\hline & & $P_{1}$ & $\begin{array}{l}\mathrm{P}_{2} \\
\mathrm{P}_{3}\end{array}$ & $P_{1}$ & $P_{2}$ & $P_{3}$ & $P_{1}$ & $\begin{array}{l}\mathrm{P}_{2} \\
\mathrm{P}_{3}\end{array}$ & $P_{1}$ & $P_{2}$ & $P_{3}$ \\
\hline 1 & 1 & 5 & 20 & 2 & 10 & 11 & 9 & 93 & 5 & 26 & 31 \\
\hline 1 & 2 & 14 & 37 & 6 & 13 & 15 & 30 & 90 & 17 & 31 & 38 \\
\hline 2 & 2 & 5 & 14 & 3 & 9 & 11 & 9 & 50 & 8 & 22 & 30 \\
\hline
\end{tabular}

\subsection{The influence of a non-constant CV on} the behaviour of the procedures

We investigated three different situations in which the variation of the $\mathrm{CV}$ was the same for both methods:

A constant standard deviation in the lower part (first $20 \%$ ) and a constant CV in the rest of the measurement range do not influence the results.
A constant CV for $80 \%$ of the measurement range, followed by an increasing $\mathrm{CV}$ up to double its size, affects the results of procedure $P_{1}$ only slightly whereas the results from procedures $P_{2}$ and $P_{3}$ become seriously impaired.$$
\text { is }
$$

A non-constant $\mathrm{CV}$ at both ends of the measurement range, however, does not lead to a further deterioration of the results.

\subsection{The influence of the sample size on the above results}

The results of our simulation study show that the estimates of the slope $\beta$ do not change if the sample size of $n=40$ is enlarged to 60 or 80 ; i.e. the bias if any - is independent of $n$. Therefore the results obtained in 4.2 to 4.5 do not depend on the sample size.

The probability of a false positive test result is also independent of $\mathrm{n}$ if the corresponding estimator is unbiased. Otherwise the actual level increases if $n$ is increased. The judgement and ranking of procedures $\mathrm{P}_{1}, \ldots, \mathrm{P}_{7}$, however, remain valid.

However, it must be stressed that these statements of independence of $\mathbf{n}$ are only valid for the average of the estimation; its precision decreases with the sample size.

\subsection{Recommendations}

There is no procedure which cân be applied without restrictions for the statistical evaluation of a method comparison unless the appropriate experimental design is used. In particular, it has been demonstrated that the quality of statistical results from $P_{2}$ and $P_{3}$ may be impaired if the sampling distribution is not uniform. Reliable statistical results, however, can be expected from procedure $P_{1}$ even if some extreme values are present, provided that the following recommendations are observed.

- The sampling distribution should be uniform. Under the usual experimental conditions, however, it is more likely to be skew. In this case the results from $\mathrm{P}_{1}$ are more reliable than those from the other procedures.

- If the precisions of both methods are identical or nearly identical then $\mathrm{P}_{1}$ is the most reliable of all the procedures, even if the CV's are not constant over the measurement range.

- If the precisions of both methods are different then $P_{1}$ gives reliable results provided that both CV's are less than $7 \%$. 
- For any other constellation of the CV's there are two possibilities:

$\mathrm{P}_{4}$ is the most appropriate of all, but the results are not invariant with respect to the assignment to $\mathrm{X}$ and $\mathrm{Y}$.

If it is required that $X$ and $Y$ can be interchanged, then without impairing the results an alternative experimental design is recommended: Single determinations should be performed with the more precise method $(\mathrm{X})$ whereas $\mathbf{k}$-fold determinations should be performed with the less precise one $(Y) . k$ is determined from

$$
k \geqslant\left(\frac{C V_{y}}{f \cdot C V_{x}}\right)^{2}
$$

where $\mathrm{f}$ is obtained from table 8 .

Tab. 8. Factor $f$ determining the number $k$ of replicate measurements for the less precise method.

\begin{tabular}{l|l}
$\mathrm{c}$ & $\mathrm{f}$ \\
\hline $\boldsymbol{x}$ & 4 \\
4 & 2 \\
2 & 1.5
\end{tabular}

If we take the mean of these $\mathrm{k}$-fold determinations for each sample we ensure that its coefficient of variation differs from $\mathrm{CV}_{\mathrm{x}}$ by the factor $\mathrm{f}$ only. Then taking as input the single values of the one method and the means of the $\mathrm{k}$-fold determinations of the other method, $\mathrm{P}_{1}$ can be used for evaluation.

\section{The Sample Size}

\subsection{The probability of a significant test re- sult}

The power of procedure $P_{1}$ if $\beta>1$ and $C_{x}=C V_{y}$ is given in tables 9,10 and 11 for different sizes $c$. The accuracy of the values is in the range of \pm 2 .

To demonstrate the dependence of the power on the simulation parameters, consider the following example: Let c be large, both CV's $7 \%, n=60$ and the sampling distribution skew, then the chance of a significant test result is about $40 \%$ if the true but unknown value of $\beta$ is 1.06 (see tab. 9).

Tab. 9. Probability of a significant test result obtained by $P_{1}$ if the size is large $(c=\infty)$ and both CV's are equal $(\gamma=5 \%)$.

\begin{tabular}{|c|c|c|c|c|c|c|c|c|c|c|c|c|c|c|c|}
\hline \multirow{3}{*}{$\begin{array}{l}\text { CV } \\
(\%)\end{array}$} & \multirow{3}{*}{$\mathrm{n}$} & \multicolumn{7}{|c|}{$\begin{array}{l}\text { Samples: uniform } \\
\text { Errors: normal }\end{array}$} & \multicolumn{7}{|c|}{$\begin{array}{l}\text { Samples: skew } \\
\text { Errors: normal }\end{array}$} \\
\hline & & \multicolumn{7}{|c|}{$\beta$} & \multicolumn{7}{|c|}{$\beta$} \\
\hline & & 1.02 & 1.04 & 1.06 & 1.08 & 1.10 & 1.15 & 1.20 & 1.02 & 1.04 & 1.06 & 1.08 & 1.10 & 1.15 & 1.20 \\
\hline 2 & $\begin{array}{l}30 \\
40 \\
50 \\
60 \\
70 \\
80 \\
90\end{array}$ & $\begin{array}{l}49 \\
65 \\
75 \\
80 \\
88 \\
92 \\
95\end{array}$ & $\begin{array}{r}97 \\
99 \\
100 \\
100 \\
100 \\
100 \\
100\end{array}$ & $\begin{array}{l}100 \\
100 \\
100 \\
100 \\
100 \\
100 \\
100\end{array}$ & $\begin{array}{l}100 \\
100 \\
100 \\
100 \\
100 \\
100 \\
100\end{array}$ & $\begin{array}{l}100 \\
100 \\
100 \\
100 \\
100 \\
100 \\
1.00\end{array}$ & $\begin{array}{l}100 \\
100 \\
100 \\
100 \\
100 \\
100 \\
100\end{array}$ & $\begin{array}{l}100 \\
100 \\
100 \\
100 \\
100 \\
100 \\
100\end{array}$ & $\begin{array}{l}31 \\
37 \\
46 \\
53 \\
60 \\
66 \\
72\end{array}$ & $\begin{array}{r}78 \\
88 \\
95 \\
98 \\
99 \\
100 \\
100\end{array}$ & $\begin{array}{r}97 \\
100 \\
100 \\
100 \\
100 \\
100 \\
100\end{array}$ & $\begin{array}{l}100 \\
100 \\
100 \\
100 \\
100 \\
100 \\
100\end{array}$ & $\begin{array}{l}100 \\
100 \\
100 \\
100 \\
100 \\
100 \\
100\end{array}$ & $\begin{array}{l}100 \\
100 \\
100 \\
100 \\
100 \\
100 \\
100\end{array}$ & $\begin{array}{l}100 \\
100 \\
100 \\
100 \\
100 \\
100 \\
100\end{array}$ \\
\hline $\begin{array}{l}7 \\
. .\end{array}$ & $\begin{array}{l}30 \\
40 \\
50 \\
60 \\
70 \\
80 \\
90\end{array}$ & $\begin{array}{l}11 \\
12 \\
13 \\
14 \\
15 \\
17 \\
20\end{array}$ & $\begin{array}{l}20 \\
27 \\
34 \\
40 \\
45 \\
49 \\
53\end{array}$ & $\begin{array}{l}41 \\
50 \\
59 \\
67 \\
75 \\
80 \\
86\end{array}$ & $\begin{array}{l}57 \\
70 \\
83 \\
90 \\
93 \\
97 \\
98\end{array}$ & $\begin{array}{r}79 \\
87 \\
94 \\
97 \\
98 \\
100 \\
100\end{array}$ & $\begin{array}{r}97 \\
100 \\
100 \\
100 \\
100 \\
100 \\
100\end{array}$ & $\begin{array}{l}100 \\
100 \\
100 \\
100 \\
100 \\
100 \\
100\end{array}$ & $\begin{array}{r}9 \\
9 \\
10 \\
11 \\
11 \\
12 \\
12\end{array}$ & $\begin{array}{l}13 \\
15 \\
19 \\
22 \\
25 \\
27 \\
29\end{array}$ & $\begin{array}{l}22 \\
28 \\
36 \\
40 \\
45 \\
52 \\
57\end{array}$ & $\begin{array}{l}35 \\
47 \\
53 \\
62 \\
70 \\
75 \\
80\end{array}$ & $\begin{array}{l}48 \\
60 \\
71 \\
81 \\
87 \\
90 \\
94\end{array}$ & $\begin{array}{r}80 \\
90 \\
95 \\
99 \\
100 \\
100 \\
100\end{array}$ & $\begin{array}{r}93 \\
99 \\
100 \\
100 \\
100 \\
100 \\
100\end{array}$ \\
\hline 13 & $\begin{array}{l}30 \\
40 \\
50 \\
60 \\
70 \\
80 \\
90\end{array}$ & $\begin{array}{l}6 \\
7 \\
7 \\
8 \\
8 \\
8 \\
9\end{array}$ & $\begin{array}{l}10 \\
11 \\
13 \\
15 \\
18 \\
20 \\
21\end{array}$ & $\begin{array}{l}15 \\
19 \\
24 \\
29 \\
32 \\
34 \\
38\end{array}$ & $\begin{array}{l}23 \\
34 \\
38 \\
44 \\
48 \\
51 \\
55\end{array}$ & $\begin{array}{l}30 \\
42 \\
51 \\
59 \\
67 \\
76 \\
83\end{array}$ & $\begin{array}{l}58 \\
70 \\
83 \\
90 \\
94 \\
98 \\
99\end{array}$ & $\begin{array}{r}79 \\
91 \\
96 \\
98 \\
99 \\
100 \\
100\end{array}$ & $\begin{array}{l}6 \\
7 \\
7 \\
8 \\
8 \\
8 \\
9\end{array}$ & $\begin{array}{r}7 \\
10 \\
10 \\
11 \\
12 \\
13 \\
16\end{array}$ & $\begin{array}{l}10 \\
12 \\
17 \\
19 \\
21 \\
22 \\
23\end{array}$ & $\begin{array}{l}16 \\
18 \\
22 \\
26 \\
30 \\
33 \\
36\end{array}$ & $\begin{array}{l}21 \\
25 \\
31 \\
36 \\
41 \\
46 \\
51\end{array}$ & $\begin{array}{l}37 \\
49 \\
58 \\
67 \\
74 \\
79 \\
84\end{array}$ & $\begin{array}{l}58 \\
66 \\
78 \\
85 \\
91 \\
94 \\
96\end{array}$ \\
\hline
\end{tabular}


Tab. 10. Probability of a significant test result obtained by $P_{1}$ if the size $c$ is medium $(c=4)$ and both CV's are equal $(\gamma=5 \%)$.

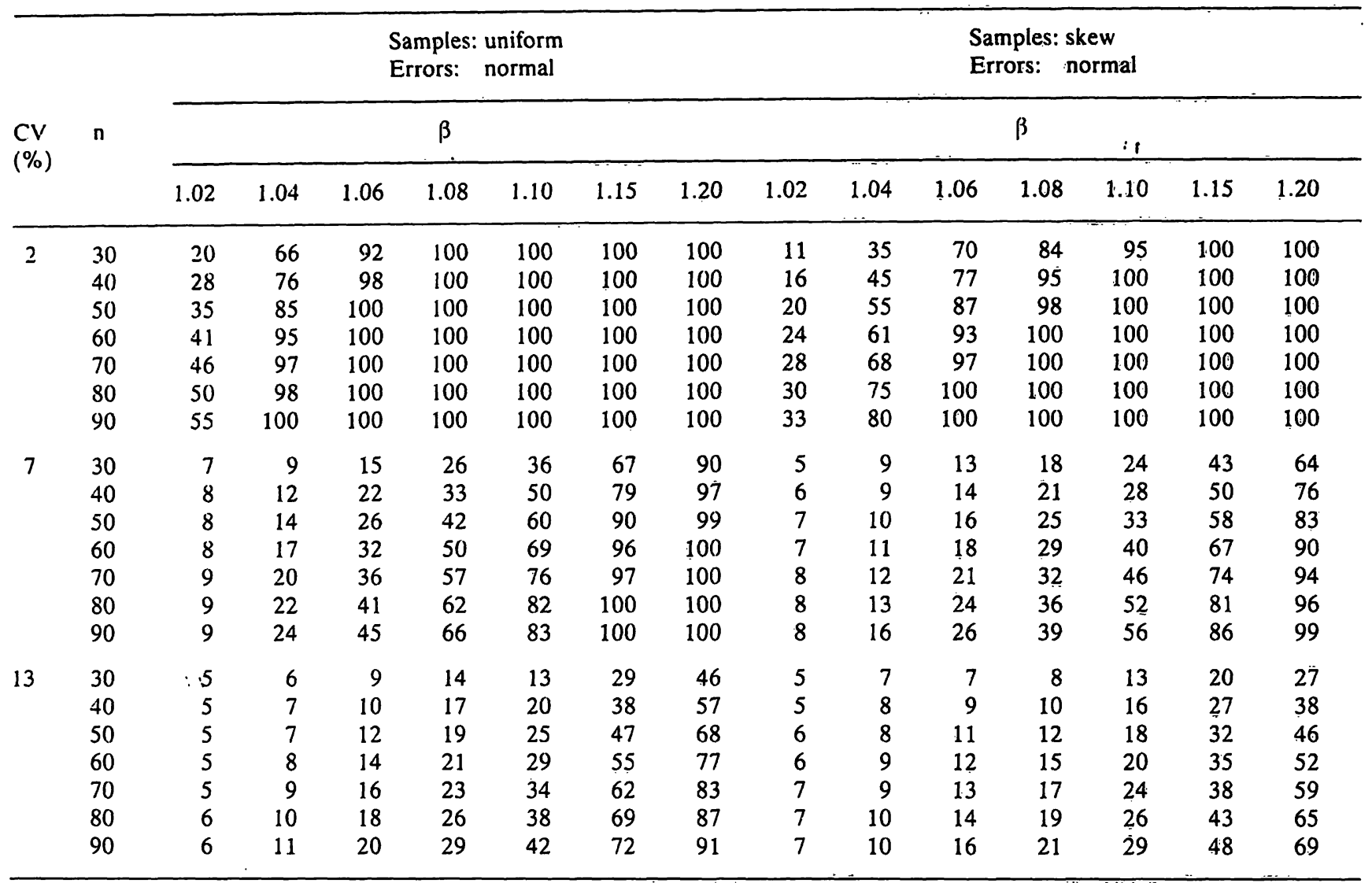

Tab. 11. Probability of a significant test result obtained by $P_{1}$ if the size $c$ is small $(c=2)$ and both CV's are equal $(\gamma=5 \%)$.

\begin{tabular}{|c|c|c|c|c|c|c|c|c|c|c|c|c|c|c|c|}
\hline \multirow{3}{*}{$\begin{array}{l}\text { CV } \\
(\%)\end{array}$} & \multirow{3}{*}{$n$} & \multicolumn{7}{|c|}{$\begin{array}{l}\text { Samples: uniform } \\
\text { Errors: normal }\end{array}$} & \multicolumn{7}{|c|}{$\begin{array}{l}\text { Samples: skew } \\
\text { Errors: normal }\end{array}$} \\
\hline & & \multicolumn{7}{|c|}{$\beta$} & \multicolumn{7}{|c|}{$\beta$} \\
\hline & & 1.02 & 1.04 & 1.06 & 1.08 & 1.10 & 1.15 & 1.20 & 1.02 & 1.04 & 1.06 & 1.08 & 1.10 & 1.15 & 1.20 \\
\hline \multirow[t]{7}{*}{2} & 30 & 10 & 26 & 50 & 77 & 92 & 100 & 100 & 7 & 16 & 24 & 43 & 58 & 86 & 97 \\
\hline & 40 & 12 & 37 & 66 & 86 & 97 & 100 & 100 & 8 & 19 & 34 & 55 & 73 & 94 & 99 \\
\hline & 50 & 14 & 42 & 73 & 91 & 99 & 100 & 100 & 9 & 22 & 41 & 66 & 82 & 98 & 100 \\
\hline & 60 & 16 & 49 & 81 & 98 & 100 & 100 & 100 & 11 & 24 & 49 & 72 & 87 & 100 & 100 \\
\hline & 70 & 18 & 56 & 86 & 99 & 100 & 100 & 100 & 12 & 27 & 57 & 77 & 91 & 100 & 100 \\
\hline & 80 & 21 & 63 & 91 & 100 & 100 & 100 & 100 & 13 & 33 & 62 & 84 & 96 & 100 & 100 \\
\hline & 90 & 23 & 69 & 93 & 100 & 100 & 100 & 100 & 14 & 35 & 65 & 88 & 97 & 100 & 100 \\
\hline \multirow[t]{7}{*}{7} & 30 & 5 & 7 & 9 & 13 & 16 & 37 & 49 & 5 & 6 & 7 & 9 & 10 & 16 & 25 \\
\hline & 40 & 5 & 7 & 11 & 17 & 21 & 41 & 60 & 5 & 7 & 8 & 11 & 14 & 20 & 38 \\
\hline & 50 & 5 & 8 & 12 & 20 & 24 & 48 & 72 & 5 & 8 & 10 & 13 & 18 & 26 & 44 \\
\hline & 60 & 6 & 9 & 14 & 22 & 31 & 55 & 79 & 6 & 8 & 11 & 16 & 21 & 32 & 53 \\
\hline & 70 & 6 & 9 & 16 & 24 & 36 & 65 & 85 & 6 & 9 & 12 & 17 & 23 & 37 & 59 \\
\hline & 80 & 7 & 10 & 17 & 27 & 41 & 72 & 92 & 6 & 9 & 13 & 18 & 27 & 42 & 67 \\
\hline & 90 & 7 & 11 & 18 & 29 & 45 & 78 & 94 & 6 & 10 & 14 & 19 & 29 & 49 & 73 \\
\hline \multirow[t]{7}{*}{10} & 30 & 5 & 5 & 6 & 9 & 13 & 20 & 30 & 5 & 5 & 6 & 7 & 9 & 15 & 21 \\
\hline & 40 & 5 & 6 & 7 & 11 & 15 & 25 & 38 & 5 & 5 & 6 & 8 & 11 & 18 & 27 \\
\hline & 50 & 5 & 8 & 8 & 12 & 18 & 31 & 47 & 5 & 6 & 7 & 9 & 12 & 22 & 32 \\
\hline & 60 & 6 & 8 & 9 & 14 & 20 & 37 & 53 & 5 & 6 & 7 & 11 & $1: 4$ & 25 & 39 \\
\hline & 70 & 6 & 9 & 11 & 16 & 22 & 44 & 62 & 6 & 6 & 8 & 13 & 16 & 29 & 43 \\
\hline & 80 & 6 & 9 & 12 & 18 & 26 & 49 & 70 & 6 & 7 & 9 & 14 & 18 & 33 & 47 \\
\hline & 90 & 6 & 9 & 14 & 20 & 29 & 52 & 73 & 6 & 7 & 9 & 15 & $\therefore 20$ & 37 & 51 \\
\hline
\end{tabular}


From the tables the following properties can be deduced:

- The power decreases with the size c. For the above example the power goes down to $11 \%$ if $c=2$ (see tab. 11). This is intuitively clear since the estimation is more precise if the size $c$ is large and a precise estimator $b_{1}$ of $\beta$ causes a high power.

- The power decreases with increasing CV's. If both CV's are $2 \%$ then the power is as high as $100 \%$ whereas if both CV's are $13 \%$ the power goes down to $19 \%$ (see tab. 9).

- The power increases with the value of $\beta$. It reaches about $100 \%$ if $\beta=1.15$. Obviously the more both methods differ from each other the better the difference can be detected (see tab. 9).

- The power increases with increasing $n$. If $n=90$ then the power goes up to $57 \%$, but the power is $22 \%$ only if $n=30$ (see tab. 9). The power approaches $100 \%$ if $n$ is large enough.

- The uniform sampling distribution leads to a higher power than the skew sampling distribution. In the above example, the power is $67 \%$ in the case of a uniform sampling distribution (see tab. 9).

Analogous statements hold if the CV's are not equal. They also remain valid if the CV's are very different and the evaluation is done by procedure $\mathrm{P}_{4}$ (see 4.7).

Therefore, the reliability of the result when testing the hypothesis $\beta=1$ depends not only on $n$ but also on the other conditions, i.e. on size $c, C V_{x}$ and $C V_{y}$, true value of $\beta$, and the sampling distribution. $A$ fixed sample size independently of these conditions cannot be recommended.

The consequences of an inappropriate sample size can be demonstrated by the above example. Let $\mathrm{c}=\infty, \mathrm{CV}_{\mathrm{x}}=\mathrm{CV}_{\mathrm{y}}=7 \%$, and let the sampling distribution be uniform. Assume that a deviation of $8 \%$ or more from $\beta=1$ is relevant, i.e. $\beta_{\text {rel }}=1.08$. If $\mathrm{n}=30$, then the power is $57 \%$ if the true but unknown $\beta$ is 1.08 ; however, the power is $79 \%$ if $\beta=$ 1.10 holds (see tab. 9). If therefore the unknown $\beta$ were 1.08 or a little bit larger, this deviation would not be detected with a sufficient probability $(\geqslant 80 \%)$, though the value of $\beta_{\text {rel }}$ would be exceeded. On the other side let $\mathrm{n}=90$. Then the power is $86 \%$ even if $\beta=1.06$ holds; i.e. this deviation would be detected as significant with a high probability even though it would not be relevant. A reasonable sample size, however, would be $n=50$. If the unknown $\beta$ exceeds the threshold $\beta_{\text {rel }}$ then the probability of a significant test result is at least $83 \%$; but for $\beta<\beta_{\text {rel }}$ this probability is lower. The sample sizes given in the next chapter are found in this way (under the assumption of identical CV's).

If the methods have different CV's then the power of the test will be different depending on whether $\beta$ or $1 / \beta$ is greater than 1 . As a consequence different sample sizes are also required. Since it is usually not known before the evaluation whether the outcome is $\beta>1$ or $1 / \beta>1$ we recommend the use of the larger sample size; the tabulated sample sizes take this into account.

\subsection{Determination of the sample size}

The common size $c$ of the measurement range of both methods is known before the beginning of an experiment. The same is true with the precisions of both methods. If the coefficients of variation do not vary too much over their concentration range the precisions may be expressed by $C V_{x}$ and $C V_{y}$. The investigator has to define by $\beta_{\text {rel }}$ a relevant difference to $\beta=1$.

If both precisions do not differ by more than the factor $f$, evaluation should be carried out by procedure $P_{1}$; table 12 gives the respective sample sizes if the sampling distribution is uniform; table 13 gives the appropriate sample sizes in the case of a skew sampling distribution. If $\mathbf{n}$ is determined in this way then the probability of detecting a relevant deviation from $\beta=1$ by procedure $P_{1}$ is about $80 \%$ or more.

It is evident that a skew sampling distribution requires a larger sample size than a uniform sampling distribution; the skew distribution as described, requires approximately twice the sample size of a uniform distribution. On the other hand, to obtain a uniformly distributed sample one needs to carry out more than the required number of determinations to achieve such a distribution. To aim for the sample size of a skew distribution may be the easier solution; the properties of procedure $P_{1}$ are still acceptable in this case.

If the precisions of both methods are different but both are less than $7 \%$ then the evaluation can be carried out by $\mathrm{P}_{1}$ and $\mathrm{n}$ is obtained from table 12 or 13.

If the precisions of both methods are different and at least one $\mathrm{CV}$ is larger than $7 \%$ then the evaluation can be performed by $P_{1}$ provided that $k$-fold determinations have been carried out for each sample of the less precise method. The value of $k$ is obtained from equation (1) and $n$ from table 12 or 13 .

The assumptions with regard to the shape of the skew sampling distribution and to normally distrib- 
Tab. 12. Proposed sample sizes for procedure $P_{1}$ if the sampling distribution is uniform $(\gamma=5 \%$; power at least $80 \%$ ).

\begin{tabular}{|c|c|c|c|c|c|c|c|c|c|c|}
\hline \multirow[b]{2}{*}{ c } & \multirow[b]{2}{*}{$\begin{array}{l}C V_{x} \\
(\%)\end{array}$} & \multirow[b]{2}{*}{$\begin{array}{l}C V_{y} \\
(\%)\end{array}$} & \multicolumn{8}{|c|}{$\begin{array}{l}\beta_{\mathrm{rcl}} \\
1 / \beta_{\mathrm{rcl}}\end{array}$} \\
\hline & & & $\begin{array}{l}1.02 \\
0.98\end{array}$ & $\begin{array}{l}1.04 \\
0.96\end{array}$ & $\begin{array}{l}1.06 \\
0.94\end{array}$ & $\begin{array}{l}1.08 \\
0.93\end{array}$ & $\begin{array}{l}1.10 \\
0.91\end{array}$ & $\begin{array}{l}1.12 \\
0.89\end{array}$ & $\begin{array}{l}1.15 \\
0.87\end{array}$ & $\begin{array}{l}1.20 \\
0.83\end{array}$ \\
\hline \multirow[t]{13}{*}{$x$} & 2 & 2 & 60 & - & - & - & - & - & - & - \\
\hline & 2 & 5 & + & 60 & 30 & - & - & - & - & - \\
\hline & 5 & 2 & + & 60 & 30 & - & - & - & - & - \\
\hline & 5 & 5 & + & 90 & 40 & 30 & - & - & - & - \\
\hline & 5 & 7 & + & + & 70 & 40 & 30 & - & - & - \\
\hline & 7 & 5 & + & + & 70 & 40 & 30 & - & - & - \\
\hline & 7 & 7 & + & + & 80 & 50 & 30 & - & - & - \\
\hline & 7 & 10 & + & + & + & 90 & 55 & 40 & 30 & - \\
\hline & 10 & 7 & + & + & + & 90 & 55 & 40 & 30 & - \\
\hline & 10 & 10 & + & + & + & 90 & 60 & 45 & 30 & - \\
\hline & 10 & 13 & + & + & + & + & 90 & 70 & 45 & - \\
\hline & 13 & 10 & + & + & + & + & 90 & 70 & 45 & - \\
\hline & 13 & 13 & + & + & + & + & 90 & 75 & 50 & 30 \\
\hline \multirow[t]{13}{*}{4} & 2 & 2 & + & 45 & - & - & - & - & - & - \\
\hline & 2 & 5 & + & + & 80 & 45 & 30 & - & - & - \\
\hline & 5 & 2 & + & + & 80 & 45 & 30 & - & - & - \\
\hline & $5: 1$ & 5 & + & + & + & 65 & 45 & - & - & - \\
\hline & 5 & 7 & + & + & + & + & 70 & 45 & 35 & - \\
\hline & 7 & 5 & + & + & + & + & 70 & 45 & 35 & - \\
\hline & 7 & 7 & + & + & + & + & 75 & 55 & 40 & - \\
\hline & 7 & 10 & + & + & + & + & + & + & 70 & 40 \\
\hline & 10 & 7 & + & + & + & + & + & + & 70 & 40 \\
\hline & 10 & 10 & + & + & + & + & + & + & 70 & 40 \\
\hline & 10 & 13 & + & + & + & + & + & + & + & 70 \\
\hline & 13 & 10 & + & + & + & + & + & + & + & 70 \\
\hline & 13 & 13 & + & + & + & + & + & + & + & 70 \\
\hline \multirow[t]{10}{*}{2} & 2 & 2 & + & + & 60 & 35 & - & - & - & - \\
\hline & 2 & 5 & + & + & + & + & + & 75 & 40 & - \\
\hline & 5 & 2 & + & + & + & + & + & 75 & 40 & - \\
\hline & 5 & 5 & + & + & + & + & + & 90 & 60 & 40 \\
\hline & 5 & 7 & + & + & + & + & + & + & 90 & 60 \\
\hline & 7 & 5 & + & + & + & + & + & $+\therefore=$ & .90 & 60 \\
\hline & 7 & 7 & + & + & + & + & + & + & + & 65 \\
\hline & 7 & 10) & + & + & + & + & + & + & + & + \\
\hline & 10 & 7 & + & + & + & + & + & + & + & + \\
\hline & 10 & 10 & + & + & + & + & + & + & + & + \\
\hline
\end{tabular}

- represents sample sizes $<30$; the value for $\beta_{\text {rel }}$ is rather large in respect to the CV's.

+ represents sample sizes $>90$.

uted measurement errors have a serious influence on the appropriate sample size; $\mathrm{n}$ would have to be increased if the sampling distribution becomes more skew. The distribution of measurement errors is generally not known; therefore we refer to a "standard" distribution. It must be noted here that the distribution of measurement errors may affect the power, but the chance of a false positive test result (i.e. if $\beta$ $=1$ is true) remains about $5 \%$.

\section{Conclusion}

Statistical evaluation of a method comparison by linear regression is completely inappropriate since it is rather likely that it produces misleading results. The results of the principal component analysis (proce- dure $P_{3}$ ) are more reliable, and those of the standardized principal component analysis (procedure $\mathrm{P}_{2}$ ) even better. But both principal component procedures show important drawbacks if the sampling distribution is skew, if the CV's are not constant over the measurement range, or if extreme values are present. Because of its robustness the new procedure $P_{1}$ can also cope with those situations; it is the regression procedure we recommend for the statistical evaluation of method comparison studies.

\section{Acknowledgement}

The authors are very grateful to $W$. Bardorff, $R$. Bender, $H .=G$. Eisenwiener, $R$. Spaethe, $W$. Specht and $E$. Völkert for their valuable comments and Prof. $B$. Schneider for his helpful suggestions. 
Tab. 13. Proposed sample sizes for procedure $P_{1}$ if the sampling distribution is skew $(\gamma=5 \%$; power at least $80 \%)$.

\begin{tabular}{|c|c|c|c|c|c|c|c|c|c|c|}
\hline \multirow[b]{2}{*}{ c } & \multirow[b]{2}{*}{$\begin{array}{l}C V_{x} \\
(\%)\end{array}$} & \multirow[b]{2}{*}{$\begin{array}{l}C V_{y} \\
(\%)\end{array}$} & \multicolumn{7}{|c|}{$\begin{array}{l}\beta_{\text {rel }} \\
1 / \beta_{\text {rel }}\end{array}$} & \multirow[b]{2}{*}{$\begin{array}{l}1.20 \\
0.83\end{array}$} \\
\hline & & & $\begin{array}{l}1.02 \\
0.98\end{array}$ & $\begin{array}{l}1.04 \\
0.96\end{array}$ & $\begin{array}{l}1.06 \\
0.94\end{array}$ & $\begin{array}{l}1.08 \\
0.93\end{array}$ & $\begin{array}{l}1.10 \\
0.91\end{array}$ & $\begin{array}{l}1.12 \\
0.89\end{array}$ & $\begin{array}{l}1.15 \\
0.87\end{array}$ & \\
\hline \multirow[t]{5}{*}{$\infty$} & 2 & 2 & + & 30 & - & - & - & - & - & - \\
\hline & 5 & 5 & + & + & 80 & 45 & 35 & - & - & - \\
\hline & 7 & 7 & + & + & + & 90 & 60 & 45 & 30 & - \\
\hline & 10 & 10 & + & + & + & + & + & 80 & 55 & 35 \\
\hline & 13 & 13 & + & + & + & + & + & + & 80 & 50 \\
\hline \multirow[t]{5}{*}{4} & 2 & 2 & + & 90 & 40 & - & - & - & - & - \\
\hline & 5 & 5 & + & + & + & + & 85 & 65 & 40 & - \\
\hline & 7 & 7 & + & + & + & + & + & + & 80 & 45 \\
\hline & 10 & 10 & + & + & + & + & + & + & + & 80 \\
\hline & 13 & 13 & + & + & + & + & + & + & + & + \\
\hline \multirow[t]{4}{*}{2} & 2 & 2 & + & + & + & 75 & 50 & 35 & - & - \\
\hline & 5 & 5 & + & + & + & + & + & + & + & 80 \\
\hline & 7 & 7 & + & + & + & + & + & + & + & + \\
\hline & 10 & 10 & + & + & + & + & + & + & + & + \\
\hline
\end{tabular}

- represents sample sizes $<30$.

+ represents sample sizes $>90$.

\section{References}

1. Passing, H. \& Bablok, W. (1983) J. Clin. Chem. Clin. Biochem. 21, 709-720.

2. Feldmann, U., Schneider, B., Klinkers, H. \& Haeckel, R. (1981) J. Clin. Chem. Clin. Biochem. 19, 121-137.

3. Averdunk, R. \& Borner, K. (1970) J. Clin. Chem. Clin. Biochem. 8, 263-268.

4. Theil, H. (1950) Proc. Kon. Akad. v. Wetensch. AS 3 Part I 386-392.

5. Ostle, B. (1963) Statistics in Research, The Iowa State University Press, Ames

6. Bartley, P., Fox B. L. \& Schrage, L. E. (1983) A Guide to Simulation, Springer Verlag, New York, Heidelberg.
7. Eisenwiener, H.-G., Bablok, W., Bardorff, W., Bender, R., Markowetz, D., Passing, H., Spaethe, R. \& Specht, W. (1983) Lab. Med. 7, 273-281.

8. Passing, H. (1981) J. Clin. Chem. Clin. Biochem. 19, 1145-1154.

9. Michotte, Y. (1978) Evaluation of precision and accuracy comparison of two procedures, In: Evaluation and optimization of laboratory methods and analytical procedures (Massart, D. L., Dijkstra, A. \& Kaufmann, L., eds.) Elsevier. Amsterdam, Oxford, New York.

\section{Dr. H. Passing}

Abtlg. für Praktische Mathematik

Hoechst AG

D-6230 Frankfurt 80

W. Bablok

Allgemeine Biometrie

Boehringer Mannheim $\mathrm{GmbH}$

D-6800 Mannheim 31 